\title{
Mitochondrial Oxidative Damage in Aging and Alzheimer's Disease: Implications for Mitochondrially Targeted Antioxidant Therapeutics
}

\author{
P. Hemachandra Reddy \\ Neurogenetics Laboratory, Neurological Sciences Institute, Oregon Health \& Science University, 505 NW 185th Avenue,
} Beaverton, OR 97006, USA

Received 8 December 2005; Revised 28 February 2006; Accepted 28 February 2006

\begin{abstract}
The overall aim of this article is to review current therapeutic strategies for treating AD, with a focus on mitochondrially targeted antioxidant treatments. Recent advances in molecular, cellular, and animal model studies of AD have revealed that amyloid precursor protein derivatives, including amyloid beta $(A \beta)$ monomers and oligomers, are likely key factors in tau hyperphosphorylation, mitochondrial oxidative damage, inflammatory changes, and synaptic failure in the brain tissue of AD patients. Several therapeutic strategies have been developed to treat $\mathrm{AD}$, including anti-inflammatory, antioxidant, and antiamyloid approaches. Among these, mitochondrial antioxidant therapy has been found to be the most efficacious in reducing pathological changes and in not producing adverse effects; thus, mitochondrial antioxidant therapy is promising as a treatment for AD patients. However, a major limitation in applying mitochondrial antioxidants to $\mathrm{AD}$ treatment has been the inability of researchers to enhance antioxidant levels in mitochondria. Recently, however, there has been a breakthrough. Researchers have recently been able to promote the entry of certain antioxidants-including MitoQ, MitoVitE, MitoPBN, MitoPeroxidase, and amino acid and peptide-based SS tetrapeptides - into mitochondria, several hundred-fold more than do natural antioxidants. Once in the mitochondria, they rapidly neutralize free radicals and decrease mitochondrial toxicity. Thus, mitochondrially targeted antioxidants are promising candidates for treating $\mathrm{AD}$ patients.
\end{abstract}

Copyright (c) 2006 P. Hemachandra Reddy. This is an open access article distributed under the Creative Commons Attribution License, which permits unrestricted use, distribution, and reproduction in any medium, provided the original work is properly cited.

\section{INTRODUCTION}

Alzheimer's disease (AD) is a complex, multifactorial, heterogeneous mental illness, which is characterized by an agedependent loss of memory and an impairment of multiple cognitive functions. $\mathrm{AD}$ is associated with the presence of intracellular neurofibrillary tangles (NFTs) and extracellular amyloid beta $(A \beta)$ plaques, the loss of neuronal subpopulations, mitochondrial oxidative damage, synaptic loss, and the proliferation of reactive astrocytes and microglia [1]. With the life span of humans increasing and with decreasing cognitive function in elderly individuals with $\mathrm{AD}$-related dementia, $\mathrm{AD}$ has become a major health problem in society. Therapeutic interventions are urgently needed to minimize the ill effects of this devastating disease. Genetic mutations are responsible for causing early onset "familial" AD (constituting only $2 \%$ of AD cases), but the causal factor(s) for the vast majority of late-onset "sporadic" $\mathrm{AD}$ cases is still unknown. In addition, cellular changes in AD neurons that occur in late-onset $\mathrm{AD}$ are also unknown. This article describes cellular changes in $\mathrm{AD}$ progression and $\mathrm{AD}$ therapeutic strategies, and then focuses on mitochondrially targeted antioxidants as potential therapies for $\mathrm{AD}$.

\section{HISTOPATHOLOGICAL AND CELLULAR CHANGES IN AD PROGRESSION}

Histological, pathological, molecular, cellular, and gene expression studies of $\mathrm{AD}$ have revealed that multiple cellular pathways are involved in $\mathrm{AD}$ progression $[2,3]$. Pathologically, there are no differences between early- and lateonset $\mathrm{AD}[4]$. In patients with late-onset $\mathrm{AD}$, pathological changes - including $A \beta$ production and deposits, NFTs, synaptic damage, and neuronal loss-occur later than in patients with early-onset $\mathrm{AD}[1,4-6]$. In contrast to early-onset $\mathrm{AD}$ in which genetic mutations accelerate the disease process, in late-onset $\mathrm{AD}$, in the absence of genetic mutation, agerelated cellular changes control AD progression [6]. Therefore, late-onset $\mathrm{AD}$ takes more time to develop [4]. Much 
research has been done on early-onset $\mathrm{AD}$ in terms of pathophysiology and cellular changes that regulate $\mathrm{AD}$ progression, but we still need more research to understand causal factors, pathophysiology, and cellular changes that are responsible for disease development and progression in lateonset AD.

Several factors are known to be involved in the development of late-onset $\mathrm{AD}$, with two of the major ones being aging [1] and mitochondrial abnormalities [5-9]. Other contributing factors are the ApoE genotype [10,11], insulindependent diabetes [12], and environmental conditions, including diet [13].

In early-onset $\mathrm{AD}$, recent molecular, cellular, and animalmodel studies have provided evidence that a $4 \mathrm{kd}$ peptide, a cleavage product of amyloid precursor proteins (APP) due to cleavage of $\beta$ and $\gamma$ secretases, is a key factor in AD development and progression [4]. The formation of the $4 \mathrm{kd} A \beta$ peptide in the brains of $\mathrm{AD}$ patients is a progressive and sequential process. Initially, soluble monomeric and oligomeric forms of 40-42 amino acid residues accumulate and later become insoluble fibrils and $A \beta$ deposits. Recent cellular and molecular studies of triple AD transgenic mice suggested that $A \beta$ production in early-onset $\mathrm{AD}$ may facilitate tau pathology [14-16]. The $A \beta$ plaques in the transgenic mice were also found to be associated with activated microglia and astrocytes and to trigger inflammatory responses [17]. In addition, recent molecular, cellular, and animal model studies have revealed that mutant APP and $A \beta$ enter mitochondria and interact with an $A \beta$-induced alcohol dehydrogenase (ABAD) protein, disrupt the electron transport chain (ETC), generate reactive oxygen species (ROS), free radicals derived from molecular oxygen in the mitochondria, and inhibit the generation of cellular adenosine triphosphate $[5,6,18,19]$. These results suggest that mutant APP and mutant $A \beta$ interacting with mitochondrial proteins cause mitochondrial dysfunction in early-onset $\mathrm{AD}[5,6,18]$.

\section{THERAPEUTIC STRATEGIES}

Recent cellular and animal model studies revealed that AD progression involves such cellular changes as inflammatory responses, mitochondrial oxidative damage, synaptic failure, and hyperphosphorylation of tau, all of which are directly related to aging and $A \beta$ production [13-16, 20-24]. Based on cellular, histopathological, and behavioral changes observed in postmortem brains of late-onset $\mathrm{AD}$ patients and in $\mathrm{AD}$ transgenic mouse models, several therapeutic strategies have been developed to treat $\mathrm{AD}$ patients, including immunotherapy [15, 25-28], anti-inflammatory therapy [29-32], antioxidant therapy [33-43], cholinergic therapy [44-51], cell cycle therapy [8, 52-54], and hormonal therapy [55-57]. This article briefly discusses four of these major therapeutic approaches, with special emphasis on mitochondrially targeted antioxidants.

\section{IMMUNOTHERAPY}

Current immunotherapeutic strategies are aimed at decreasing $A \beta$ levels in late-onset $\mathrm{AD}$ patients by inhibiting $A \beta$ generation [58], reducing soluble $A \beta$ levels $[59,60]$, and enhancing $A \beta$ clearance from the brain $[15,26-28]$.

Immunization of $A \beta$ in $\mathrm{AD}$ transgenic mouse models has shown that $A \beta$ levels can be reduced in the brains of $\mathrm{AD}$ mice [14, 25-27]. With encouraging results from in vivo studies that have aimed at abolishing $A \beta$ deposits in cellular and animal models of AD, Elan Pharmaceuticals moved quickly to investigate, in phase II clinical trials, immunotherapy to reduce $A \beta$ [25]. However, this research was stopped because AD subjects developed symptoms of aseptic meningoencephalitis [25]. The following critical issues need to be addressed before resuming immunotherapy clinical trials using $\mathrm{AD}$ subjects: (1) the long-term consequences of $A \beta$ immunization for the $\mathrm{AD}$ brain need to be identified, (2) even though immunotherapy has been found to clear $A \beta$ deposits in the $\mathrm{AD}$ brain, the downstream effects of $\mathrm{AD}$ progression still need to be determined, and (3) the relationship between the clearing of $A \beta$ and the improvement of cognitive function in $\mathrm{AD}$ patients needs to be clarified. Currently, several laboratories are actively involved in immunotherapy research to clear both soluble and insoluble $A \beta$ from the brain and to improve behavioral changes in AD transgenic mice.

\section{ANTI-INFLAMMATORY THERAPY}

Inflammation of brain tissue is an important component in the pathogenesis of $\mathrm{AD}$, involving the activation of both microglia and astrocytes. Recent histological studies have revealed the presence of activated microglia and reactive astrocytes in and around extraneuronal $A \beta$ plaques in brains from AD patients. These activated microglia and reactive astrocytes are believed to facilitate the clearing of $A \beta$ deposits from the brain parenchyma [13]. However, now there is increasing evidence to suggest that the chronic activation of microglia, presumably via the secretion of cytokines and reactive molecules $[61,62]$, may exacerbate $A \beta$ plaque pathology as well as enhance the hyperphosphorylation of tau and the formation of NFTs [14-16]. Thus, the suppression of microglial activity in the AD brain has been considered a possible therapeutic strategy to treat AD patients $[13,30]$. Suppressive anti-inflammatory drugs, particularly nonsteroidal anti-inflammatory drugs, have been found to lessen the effects of $A \beta$ in transgenic mice [29-32].

\section{CHOLINERGIC THERAPY}

$\mathrm{AD}$ affects cholinergic neurotransmission in the neurons of the basal forebrain [63]. There is increasing evidence that the enzymes involved in the synthesis of choline acetyltransferase (ChAT) and the degradation of acetylcholine (ACh) may be responsible for deficits in cholinergic neurotransmission. Strategies to boost the levels of ACh in the AD brain are being developed to treat AD patients, to reduce NFTs and $A \beta$ levels, and to improve cognition. Similar to ChAT, butylcholinesterase (BChE) inactivates the neurotransmitter $\mathrm{ACh}$ and, thus, is a viable therapeutic target for $\mathrm{AD}$. Greig et al [47] tested potent, reversible, and brain-targeted BChE inhibitors (cymserine analogs). In rats, cymserine 
analogs caused long-term inhibition of brain BChE and elevated extracellular ACh levels, without inhibiting ChAT [47]. In slices from rat brains, selective $\mathrm{BChE}$ inhibition augmented long-term potentiation. These compounds (cymserine analogs) improved the cognitive performance (maze navigation) of aged rats. In cultured human SK-N-SH neuroblastoma $(\mathrm{N} 2 \mathrm{a})$ cells, BChE inhibitors reduced intra- and extracellular $A \beta$ precursor proteins and secreted $A \beta$ peptides without affecting cell viability. Cholinergic treatment of transgenic mice overexpressing human mutant APP also resulted in lower levels of $A \beta$ peptides in their brains than the levels of $A \beta$ peptides in the brains from healthy (control) rats. Selective, reversible inhibition of brain BChE may be a viable treatment for $\mathrm{AD}$ to improve cognition and to modulate neuropathological markers of the disease. Discoveries in cholinergic therapeutics have already led to the development of several cholinesterase inhibitors [44-51]. Four cholinesteraseinhibiting drugs are currently being prescribed for patients with mild to moderate AD: Donepezil, Rivastigmine, Galantamine, and Tacrine. However, these drugs provide only temporary relief of $\mathrm{AD}$ symptoms, and there is no evidence as yet to suggest that they reduce AD pathology. As a result, cholinergic therapy is considered a short-term intervention for certain symptoms of $\mathrm{AD}$, since it is still unknown whether cholinesterase inhibitors modify $A \beta$ pathology in AD mouse models and in $\mathrm{AD}$ patients. This issue has been under intense investigation in many laboratories across the world.

\section{OXIDATIVE STRESS AND ANTIOXIDANT THERAPY}

Oxidative stress is a major factor associated with the development and progression of $\mathrm{AD}$ and other forms of dementia. A large body of data suggests that free radical oxidative damage - particularly of neuronal lipids $[64,65]$, nucleic acids $[23,24,66-68]$, and proteins $[66,67,69,70]$ - is extensive in the brains of $\mathrm{AD}$ patients. Increased oxidative stress is thought to result in the generation of free radicals and ROS, which is reported to be released by microglia activated by $A \beta$ $[71,72]$. Compared to other organs, the brain has been found to be more vulnerable to oxidative stress due to its high lipid content, its relatively high oxygen metabolism, and its low level of antioxidant defenses [70, 73, 74]. Markers of oxidative stress, such as 8-hydroxyguanosine and hemeoxygenase, have been localized to pathologic lesions in the brains of AD patients [75-78].

Using PC 12 cells and $A \beta(25-35)$ peptide, Bozner et al studied the connection between $A \beta$ and mitochondrial DNA damage. They exposed PC 12 cells to an $A \beta$ (25-35) in frame and scrambled at $50 \mathrm{mM}$ concentration for 24 hours to 50 hours. Oxidative damage of mitochondrial DNA was assessed using a Southern blot technique and a mitochondrial DNA-specific probe recognizing a 13.5-kilobase restriction fragment. PC 12 cells exposed to $A \beta$ exhibited marked oxidative damage of mitochondrial DNA as evidenced by characteristic changes on Southern blots, but not in cells exposed to the scrambled $A \beta$ peptide, suggesting that $A \beta$ peptide is responsible for mitochondrial DNA damage, and ultimately leading to mitochondrial dysfunction in $\mathrm{AD}$ [68]. Further, evidence from a recent gene expression study [21] suggests that mutant APP or $A \beta$ may generate free radicals and promote mitochondrial dysfunction, one or both of which may lead to oxidative damage. Altered levels of mitochondrial enzymes have been found to be directly responsible for a decrease in energy production in the brains of late-stage AD patients [5]. Soluble or insoluble forms of $A \beta$ have been suggested to impair ATP production by generating defects in mitochondrial energy metabolism and oxidative stress [79]. Taken together, these results suggest that oxidative stress is a key event in $\mathrm{AD}$ pathogenesis.

\section{FREE RADICAL PRODUCTION AND MITOCHONDRIAL OXIDATIVE DAMAGE}

In the literature on $\mathrm{AD}$, the terms "oxidative stress" or "oxidative damage" are commonly used to explain the balance between the production of oxidants and the endogenous antioxidant defenses in neuronal cells. In general, cells undergo apoptotic death when there is an imbalance between oxidants and antioxidants (more oxidants than antioxidant defenses). This oxidative damage mainly occurs via the mitochondrial ETC $[5,6]$.

Mitochondria, which are cytoplasmic organelles, are responsible for the production of cellular ATP. Mitochondria are involved in 3 important cell functions: (1) producing ATP and regulating intracellular $\mathrm{Ca}^{2+}$; (2) releasing proteins that activate the caspase family of proteases; and (3) altering the reduction-oxidation potential of cells [5]. Disruption of the ETC has been recognized as an early characteristic of apoptotic cell death. ETC involves the reduction of hydrogen peroxide $\left(\mathrm{H}_{2} \mathrm{O}_{2}\right)$ to $\mathrm{H}_{2} \mathrm{O}$ and $\mathrm{O}_{2}$ by catalase or glutathione peroxidase accepting electrons donated by NADH and $\mathrm{FADH}_{2}$, and then yielding energy for the generation of ATP from adenosine diphosphate and inorganic phosphate [6, 80-82].

The production of mitochondrial superoxide radicals $\left(\mathrm{O}_{2}^{\bullet-}\right)$ occurs primarily at discrete points in the ETC at complexes 1 and 3 [83], and in components of tricarboxylic acid (TCA), including $\alpha$-ketoglutarate dehydrogenase [84] (see Figure 1). In addition, mitochondrial $\mathrm{O}_{2}^{\bullet-}$ are generated in the outer mitochondrial membrane. Monoamine oxidase (flavoprotein), localized on the outer mitochondrial membrane, catalyzes the oxidative deamination of primary aromatic amines. This deamination is a quantitatively large source of $\mathrm{H}_{2} \mathrm{O}_{2}$ that contributes to an increase in the steadystate concentrations of ROS within both the mitochondrial matrix and the cytosol [80]. These released $\mathrm{H}_{2} \mathrm{O}_{2}$ and $\mathrm{O}_{2}^{\bullet-}$ are carried to the cytoplasm via voltage-dependent anion channels and, ultimately, lead to the oxidation of cytoplasmic proteins (see Figure 1). The chronic exposure of ROS to cells can result in oxidative damage to mitochondrial and cellular proteins, lipids, and nucleic acids, and acute exposure to ROS can inactivate the TCA-cycle aconitase and the ironsulfur centers of ETC at complexes 1,2, and 3, resulting in a shutdown of mitochondrial energy production $[5,6,85]$.

The generation of free radicals can occur via several cellular insults, including ultraviolet irradiation [86], redoxcycling of quinones [86], the metabolism of xenobiotics [86], 


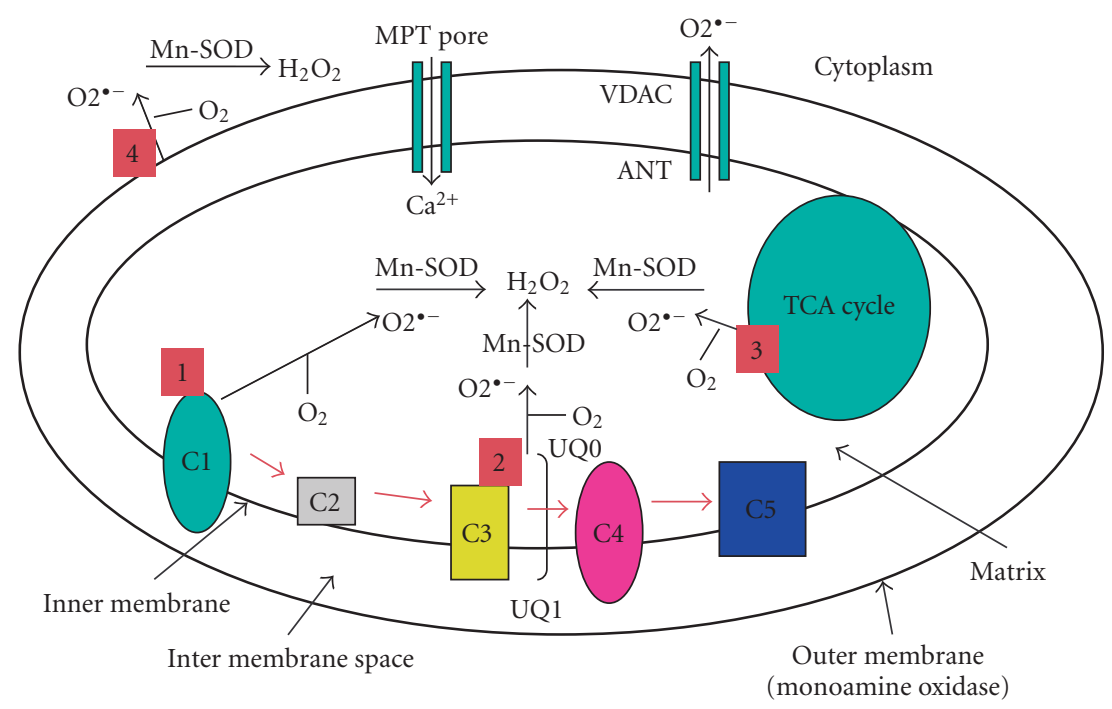

FIGURE 1: Illustration of sites of free radical generation in the mitochondria. In the respiratory chain, complexes 1 and 3 leak electrons to oxygen, producing primarily superoxide radicals $\left(\right.$ or $\mathrm{O}_{2}^{--}$). The $\mathrm{O}_{2}^{--}$are dismutated by manganese superoxide dismutase to generate $\mathrm{H}_{2} \mathrm{O}_{2}$ and oxygen. Complex 1 generates $\mathrm{O}_{2}^{\bullet^{-}}$only toward the matrix. Complex 3 , on the other hand, generates $\mathrm{O}_{2}^{\bullet^{-}}$toward both the intermembrane space and the matrix. The components of tricarboxylic acid, including $\alpha$-ketoglutarate dehydrogenase, also generate $\mathrm{O}_{2}^{\cdot-}$ in the matrix. Free radicals are generated in the outer mitochondrial membrane (monoamine oxidase) and catalyze the oxidative deamination of primary aromatic amines, leading to the generation of $\mathrm{H}_{2} \mathrm{O}_{2}$.

aging [87], environmental mitochondrial toxins [88-90], and mutant toxic proteins (eg, $A \beta$ in $\mathrm{AD}$, mutant huntingtin in Huntington's disease, alpha-synuclein in Parkinson's disease, mutant SOD1 in amyotrophic lateral sclerosis) $[5,8,87]$.

\section{FREE RADICALS, ABNORMAL PROCESSING OF APP, AND $A \beta$ METABOLISM}

There is mounting evidence to suggest that in late-onset $\mathrm{AD}$, age-related free radicals, which are generated in the mitochondria, are carried to the cytoplasm where they activate beta secretase and facilitate the cleavage of the APP molecule [6]. The cleaved APP molecule (ie, $A \beta$ ) further generates free radicals, leading to the disruption of the ETC and enzyme activities, the inhibition of ATP, and the subsequent oxidation of both nuclear and mitochondrial DNA proteins. The damage caused by mitochondria ultimately leads to neuronal damage, neurodegeneration, and cognitive decline in $\mathrm{AD}$ patients [6].

\section{AGE-DEPENDENT MITOCHONDRIAL $\mathrm{Ca}^{2+}$ AND OXIDATIVE DAMAGE}

The dysregulation of age-related $\mathrm{Ca}^{2+}$ and an increased production of ROS may contribute to late-onset neurodegenerative disorders such as AD. These alterations are often attributed to impaired mitochondrial function, yet few studies have directly examined isolated mitochondria from various regions of the aged brain. Recently, Brown et al [91] examined $\mathrm{Ca}^{2+}$ influx and ROS production in isolated mitochondria from Fischer 344 rats ranging in age from 4 to
25 months. Isolated mitochondria from the cortex of the 25month-old rat brain exhibited greater rates of ROS production and mitochondrial swelling in response to increasing $\mathrm{Ca}^{2+}$ loads compared to mitochondria isolated from younger (4- and 13-month-old) rats. This increased swelling is indicative of the opening of a mitochondrial permeability transition pore, suggesting an impaired $\mathrm{Ca}^{2+}$ influx in aged animals (see Figure 1). These age-related differences were not observed in isolated mitochondria from the cerebellum of these rats. Together, these results suggest region-specific, agerelated alterations in mitochondrial responses to $\mathrm{Ca}^{2+}[91]$. In addition to aging, in age-related diseases such as $A D$, $A \beta$ promotes the opening of the mitochondrial permeability transition pore, through which free cytosolic $\mathrm{Ca}^{2+}$ enter the mitochondria (see Figure 1). The mitochondrial $\mathrm{Ca}^{2+}$ may disrupt the ETC, which would elevate the production of free radicals in the mitochondria [92]. To determine the extent of free radical production and oxidative damage in the spinal cord and neocortex of the rat brain, Sullivan et al [93] studied several parameters of mitochondrial physiology in the normal neocortex and spinal cord. In situ measurements revealed significantly higher levels of $\mathrm{O}_{2}^{\bullet-}$ production, lipid peroxidation, and mitochondrial DNA oxidation in the spinal cord than these levels in neocortical neurons. Real-time PCR analysis of mitochondrial genes demonstrated differences in mitochondrial transcripts coupled with decreases in complex 1 enzyme activity and in respiration, in the spinal cord mitochondria. The threshold for calciuminduced mitochondrial permeability transition was substantially reduced in the spinal cord relative to the neocortex and was modulated by lipid peroxidation. These findings suggest that studying mitochondrial damage in the spinal cord may 
be productive in learning about causes of age-related neurodegenerative diseases [93].

\section{A $\beta$ AND MITOCHONDRIAL FUNCTIONAL ASSOCIATION}

To determine whether mitochondria are critical for cellular toxicity induced by $A \beta$, Cardoso et al [94] investigated the effects of $A \beta$ peptides in NT2 cells with mitochondria (NT2 $-P+)$ and without mitochondria (NT2 -P0) [94]. In NT2 $P+$ cells, they observed a decrease in cell viability, mitochondrial membrane potential, enzyme activities, and ATP levels, but they did not find such decreases in NT2 - P0 cells, suggesting that $A \beta$ peptides require functional mitochondria for the induction of cell toxicity. Further, several studies reported the association of mutant APP derivatives with mitochondria [18, 19, 95]. Anandatheerthavarada et al [95] observed that in cortical neurons, the accumulation of full-length APP in the mitochondrial compartment in a transmembranearrested form of APP is responsible for mitochondrial dysfunction and impaired energy metabolism [95]. Lustbader et al [18] demonstrated that $A \beta$ is localized to mitochondria in the neurons of $\mathrm{AD}$ transgenic mice. Further, they also found that $A \beta$ directly interacts with an $A \beta$-binding $A B A D$ protein in the mitochondria, leading to oxidative damage and mitochondrial dysfunction [18]. Crouch et al [19] studied the inhibitory potential of synthetic $A \beta(1-42)$ on the activity of ETC enzyme complexes in human mitochondria. They found that synthetic $A \beta(1-42)$ inhibits the terminal complex cytochrome $c$ oxidase in a manner that is dependent on the presence of $\mathrm{Cu}^{2+}$. In the Crouch study, maximal cytochrome $c$ oxidase inhibition occurred when synthetic $A \beta(1-42)$ solutions were used after they aged from 3 to 6 hours at $30^{\circ} \mathrm{C}$. The level of $A \beta$ (1-42)-mediated cytochrome $c$ oxidase inhibition increased up to 6 hours after the $A \beta$ (1-42) solution aged, and then the level declined progressively as the $A \beta(1-42)$ solutions aged to 48 hours. These data strongly suggest that endogenous $A \beta$ is associated with brain mitochondria and that synthetic $A \beta(1-42)$ is a potent inhibitor of cytochrome $c$ oxidase [19]. All of these studies combine to suggest that mitochondria are vulnerable to $A \beta$ and/or age-related oxidative damage.

\section{ANTIOXIDANT TREATMENT}

Using a Tg2576 mouse model of AD and treating the Tg2576 mice with a vitamin E-supplemented diet, researchers in in vivo studies reported decreased $A \beta(1-40)$ and $A \beta(1-42)$ levels $[34,35]$. In another study, researchers using a transgenic mouse model of tau pathology found that the administration of vitamin E ameliorated tau aggregates [33], suggesting that vitamin $\mathrm{E}$ may have a direct effect on $\mathrm{AD}$ pathology $[34,35]$. The administration of curcumin (an antioxidant) to Tg2576 mice also showed encouraging results when both oxidative damage and $A \beta$ deposits were reduced [38]. Further, melatonin reduced brain levels of $A \beta$ and abnormal protein nitration, and increased the life span of Tg2576 mice [36]. A synthetic superoxide (a dismutase catalase mimetic) prevented cataracts in AD transgenic mice [96].
Several recent antioxidant studies using AD patients revealed beneficial effects of diets supplemented with vitamin $\mathrm{E}$ $[39,40,42]$. The combined administration of vitamin $\mathrm{E}$ and vitamin $C$ supplements was associated with a reduced prevalence and incidence of $\mathrm{AD}$ in an elderly population [43]. Morris et al [41] examined whether food intake of vitamin $\mathrm{E}$, alpha-tocopherol equivalents (a measure of the relative biologic activity of tocopherols and tocotrienols), or individual tocopherols protects against AD symptoms and cognitive decline. They found that higher intake of vitamin $\mathrm{E}$ and alpha-tocopherol equivalents was associated with a reduced incidence of $\mathrm{AD}$ in an elderly population, suggesting that antioxidant treatment at the early onset of disease may be effective in delaying AD progression [41]. However, the pathological effects of oxidative stress are yet to be assessed in AD patients or elderly individuals treated with antioxidants. In another clinical study, to determine the neuroprotective effects of cholinesterase inhibition and oxidative stress in $\mathrm{AD}$ patients, huperzine A (an antioxidant) was administered to $\mathrm{AD}$ patients in doses of $300 \mathrm{mg} / \mathrm{d}$ for the first 2-3 weeks of drug administration and then $400 \mathrm{mg} / \mathrm{d}$ for the next $4-12$ weeks. At the end of 12 weeks, the AD patients exhibited significant improvement in their cognitive, noncognitive, and ADL functions [97]. These initial clinical trials may eventually become precursors for antioxidant clinical trials for AD patients.

\section{MITOCHONDRIALLY TARGETED ANTIOXIDANT THERAPIES IN AGING AND AD}

Krzepilko et al [98] studied exogenous mitochondrial antioxidants in yeast (Saccharomyces cerevisiae) mutants. They found that yeast mutants lacking CuZn-superoxide dismutase are hypersensitive to oxygen and have a significantly decreased replicative life span [98]. These defects can be ameliorated by the low-molecular weight exogenous antioxidant ascorbate. The effect of ascorbate on life span is complicated by its auto-oxidation in yeast cell culture media. Krzepilko and colleagues found that if negative effects of auto-oxidation are prevented by exchange of the medium, ascorbate prolongs not only the mean but also the maximal replicative life span of the yeast in an atmosphere of air and pure oxygen. The findings from this study suggest that the shortening of a healthy life span due to the lack of an antioxidant enzyme may be ameliorated by ascorbate [98].

In studies of the transgenic fruit fly Drosophila that overexpresses antioxidant enzymes targeted to mitochondria, Ruan et al [99] found that the antioxidant enzymes Mn-SOD (manganesesuperoxide dismutase) and methionine sulfoxide reductase extended the life span of Drosophila, suggesting that mitochondrially targeted antioxidants may reduce ROS and contribute to life span extension [99]. However, recently, Magwere et al [100] tested the effects of SOD mimetic drugs Euk-8 and -134, and the mitochondrially targeted mitoquinone (MitoQ) on life span and oxidative stress resistance of wild-type and SOD-deficient flies. They confirmed findings from other researchers that exogenous antioxidants rescue pathology associated with compromised deficiencies 
to oxidative stress, but do not extend the life span of normal, wild-type flies treated with exogenous antioxidants. All three exogenous antioxidants (Mn-SOD, MitoQ, and Euk- 8 and -134) led to a dose-dependent increase in toxicity in wildtype flies, an effect that was exacerbated in the presence of the redox-cycling drug, paraquat. However, important findings from this study were that in SOD-deficient flies, the antioxidant drugs increased life span. Further, the effects of these antioxidant drugs were sex-specific, and for either sex, the effects were also variable depending on (1) the stage of development at which the drugs were given, and (2) the magnitude of the dose [100].

Schriner et al [101] recently demonstrated that mitochondrially targeted catalase decreases $\mathrm{H}_{2} \mathrm{O}_{2}$, leads to reduced mitochondrial oxidative damage, and increases the life span of catalase transgenic mice. To determine the role of catalase in mitochondrial function, they created mouse lines that overexpress human catalase localized to peroxisomes, nuclei, and mitochondria, to elucidate the effects of catalase on aging from birth to death. Catalase, found mainly in peroxisomes, rapidly converts toxic $\mathrm{H}_{2} \mathrm{O}_{2}$ into $\mathrm{H}_{2} \mathrm{O}$ and $\mathrm{O}_{2}$ [6]. In two independent lines of mitochondrial catalase (MCAT) mice, Schriner et al [101] found that the transgenic mice treated with MCAT expressers showed about a $20 \%$ increase in median and maximal life span (on average, 5.5 months) compared to the life span of nontransgenic, age-matched wild-type littermates. The ability of catalase to increase longevity was most apparent when the enzyme was targeted to mitochondria. Schriner et al found that the transgenic mice, which express catalase in peroxisome, had a slightly longer median life span, but showed no increase in maximal life. Nuclear catalase (NCAT) expression (in NCAT mice) had no effect on either the median life span or the maximal life span of the mice [101].

In the Schriner study [101], MCAT transgenic mice appeared to age more slowly than their age-matched littermates by several measures. While histological comparisons showed little difference between wild-type and MCAT lines in young mice ( 9 to 11 months old), aged transgenic mice (20 to 25 months old) had significantly less arteriosclerosis and cardiomyopathy than their wild-type littermates. Biochemical studies have shown that the slower aging found in the MCAT mice is associated with a lower level of oxidative stress and DNA damage [101]. In the Schriner study [101], $\mathrm{H}_{2} \mathrm{O}_{2}$ production by cardiac mitochondria from MCAT mice decreased $25 \%$, and mitochondria containing catalase were protected from the toxic effects of $\mathrm{H}_{2} \mathrm{O}_{2}$. Age-related increases in oxidative damage to total DNA and fragmentation of mitochondrial DNA were also slowed in the skeletal muscle of MCAT mice [101].

Overall, findings from these aging studies suggest that mitochondrially targeted antioxidants reduce ROS production and oxidative damage in that the flies were diseased and also contribute to healthy aging at least in laboratory mice. However, the effects of mitochondrial antioxidants in healthy humans and humans with neurodegenerative disease still need to be determined.
From these aging studies, it is clear that mitochondrially generated $\mathrm{H}_{2} \mathrm{O}_{2}$ is a critical factor in determining life span. If aging is a key to the generation of $\mathrm{H}_{2} \mathrm{O}_{2}$ in aged neurons, then mitochondrially targeted catalase, glutathione peroxidase, MitoQ [102], MitoVitE [103], MitoPBN [104], and several mitochondrially targeted peptides $[105,106]$ may likely, rapidly convert toxic $\mathrm{H}_{2} \mathrm{O}_{2}$ into $\mathrm{H}_{2} \mathrm{O}$ and $\mathrm{O}_{2}$. This continuous conversion of $\mathrm{H}_{2} \mathrm{O}_{2}$ into $\mathrm{H}_{2} \mathrm{O}$ and $\mathrm{O}_{2}$ may reduce oxidative damage in aged neurons and may maintain mitochondrial function in the neurons of aged individuals. It has been established that an overload of $\mathrm{Ca}^{2+}$ induces ROS and disrupts the ETC in mitochondria. It is also possible that mitochondrially targeted antioxidants reduce ROS induced by an age-related overload of $\mathrm{Ca}^{2+}$ in mitochondria [91, 92]. Since age is a major factor involved in the development of late-onset $\mathrm{AD}$, mitochondrially targeted antioxidants may be able to reduce oxidative damage in $\mathrm{AD}$, increase $\mathrm{O}_{2}$ consumption, help increase the life span of elderly individuals, and decrease or prevent $\mathrm{AD}$ progression in elderly individuals [6].

A major limitation in using antioxidant therapy to treat the age-related diseases, such as $\mathrm{AD}$, has been the inability of investigators to enhance the antioxidant levels in mitochondria [107]. However, in the last 5 years, considerable progress has been made in developing mitochondrially targeted antioxidants. To increase the delivery of antioxidants to mitochondria, three types of antioxidants are being studied: triphenylphosphonium-based antioxidants, and amino acid- and peptide-based antioxidants.

\section{HOW DO MITOCHONDRIALLY TARGETED ANTIOXIDANTS ENTER MITOCHONDRIA?}

The mitochondrial ETC participates in the transfer of electrons to $\mathrm{O}_{2}$ [6]. During this transfer, a proton gradient is generated, which drives the production of ATP by ATPsynthase [86]. ATP production in turn generates a negative potential from 150 to $180 \mathrm{mV}$ across the inner mitochondrial membrane. This negative potential gradient is used to deliver liphophilic cations to mitochondria. The liphophilic cations easily permeate through the lipid bilayers and subsequently accumulate by several hundred-fold within the mitochondria, given their large mitochondrial membrane potential (see Figure 2). Using this known transfer of electrons to $\mathrm{O}_{2}$, Murphy and colleagues recently developed several mitochondrially targeted antioxidants: MitoQ (a derivative of mitochondrial quinoline), MitoVitE (a derivative of mitochondrially targeted vitamin E) [102, 107], and MitoPBN (a derivative of $\alpha$-phenyl-N-tert-butyl nitrone) [104]. These liphophilic cations-based antioxidants were covalently coupled to a triphenylphosphonium cation and were preferentially taken up by mitochondria [102-104]. These antioxidants initially accumulated in the cytoplasm of cells, due to a negative plasma membrane potential (see Figure 2) [102, 107, 108]. 


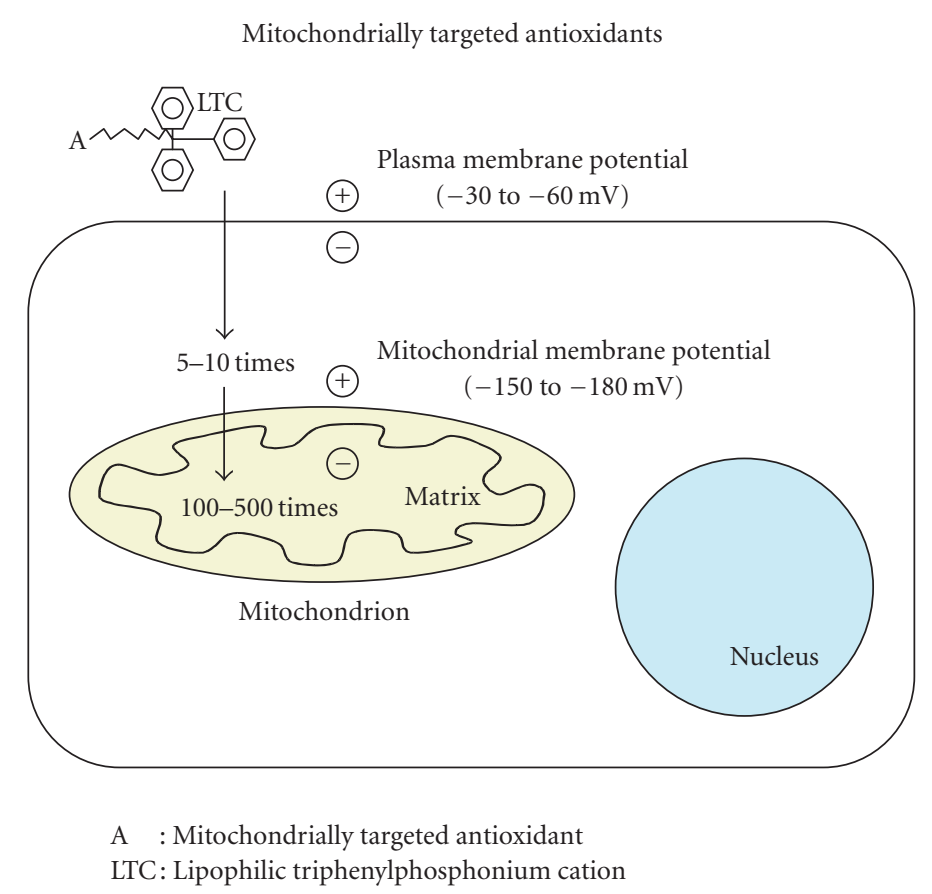

FIGURE 2: Illustration of mitochondrially targeted antioxidants. A generic mitochondria-targeted antioxidant is shown constructed by the covalent attachment of an antioxidant molecule to the lipophilic triphenylphosphonium cation. Antioxidant molecules accumulate 5- to 10 -fold in the cytoplasm, which is driven by the plasma membrane potential, and then further accumulate several hundred-fold in the mitochondria.

\section{MitoQ}

MitoQ is an antioxidant consisting of two redox forms of mitochondrially targeted ubiquinone derivatives: reduced mitoquinol and oxidized mitoquinone [102]. MitoQ is attached to a phosphonium cation [10-(6-ubiquinonyl) decyltriphenylphosphonium bromide]. The molecular formula of Mito $\mathrm{Q}$ is $\mathrm{C}_{37} \mathrm{H}_{46} \mathrm{O}_{4} \mathrm{PBr}$, and its molecular weight is 665.65 . MitoQ is a red, oily solid and can be stored at $-20^{\circ} \mathrm{C}$ in the dark. It can be converted into a fully oxidized form by incubation in $95 \%$ ethanol and can be dissolved in DMSO.

MitoQ is a promising therapeutic antioxidant that has been successfully targeted to mitochondria [102]. MitoQ is a respiratory chain component buried within the lipid core of the inner membrane of mitochondria where it accepts 2 electrons from complex 1 or 2 , to form the reduction product ubiquinol, which donates electrons to complex 3 [109]. The ubiquinone pool in vivo exists largely in a reduced ubiquinol form, acting as an antioxidant and a mobile electron transfer. Ubiquinol has been reported to function as an antioxidant by donating a hydrogen atom from one of its hydroxyl groups to a lipid peroxyl radical, thereby decreasing lipid peroxidation within the mitochondrial inner membrane [110-112]. The semiubiquinone radical formed during this process disproportionates into ubiquinone and ubiquinol [113]. The respiratory chain subsequently recycles ubiquinone back to ubiquinol, restoring its antioxidant function. MitoQ excessively accumulates in the mitochondria and converts $\mathrm{H}_{2} \mathrm{O}_{2}$ to $\mathrm{H}_{2} \mathrm{O}$ and $\mathrm{O}_{2}$, and reduces toxic insults from free radicals in the mitochondria. This reduction ultimately leads to the protection of neurons from age-related and/or disease-related mitochondrial insults in $\mathrm{AD}$.

Recently, the effects of MitoQ on mitochondria in several in vitro cell models were tested [114-117]. In cultured fibroblasts from Friedreich Ataxia patients, MitoQ prevented cell death known to be caused by endogenous oxidative stress [115]. In a study of PC12 cells, low concentrations of MitoQ $(1 \mu \mathrm{M})$ selectively inhibited serum deprivation-induced apoptosis in PC12 cells [116]. In a study of bovine aortic endothelial cells treated with glucose/glucose oxidase and lipid peroxide, MitoQ inhibited cytochrome $c$ release, caspase 3 activation, and DNA fragmentation in greater percentages than did the corresponding untargeted counterparts such as vitamin E [117]. These studies suggest that MitoQ may reduce free radicals, decrease oxidative damage, and maintain mitochondrial function. Since oxidative damage is part of the known pathophysiology of $\mathrm{AD}$, there is strong interest in determining whether mitochondrially targeted antioxidants decrease oxidative damage in the neurons of $\mathrm{AD}$ patients [6].

Smith et al [118] studied the effects of mitochondrially targeted antioxidants, including MitoQ, on laboratory mice. Some of the mice were fed with MitoQ for several weeks until MitoQ reached steady-state concentrations within all tissues assessed, including brain, heart, liver, and kidney tissues [118]. At that point, the concentration of MitoQ in the tissues was several hundred-fold higher than that in the bloodstream. Smith et al [118] found the uptake of MitoQ to be reversible, as observed by the rapid clearance of the simple 
lipophilic cation methyltriphenylphosphonium from all organs when oral administration of MitoVitE was stopped. Using mass spectrometry, they found that orally administered MitoQ entered the bloodstream and distributed in an intact active form to tissues in the brain, heart, and liver. After the mice were fed with methyltriphenylphosphonium and $\mathrm{Mi}$ toVitE, the levels of these accumulated antioxidants were in the range of 5 to $20 \mathrm{nmol} / \mathrm{g}$ (wet weight), or about 5 to 20 $\mu \mathrm{mol} / \mathrm{l}$ in the tissues [118]. These high concentrations may be in a therapeutic range since Mito $Q$ has been found to prevent oxidative damage in isolated mitochondria at lower concentrations (eg, 1 to $2.5 \mu \mathrm{mol} / 1[102,103])$. Therefore, the oral administration of well-tolerated doses of MitoQ may deliver potentially therapeutic concentrations to mitochondria in vivo [118].

Further, Adlam et al [119] recently examined the effect of MitoQ in a murine model of cardiac ischemia-reperfusion injury (a mitochondrial oxidative damage model). MitoQ fed to rats significantly decreased their heart dysfunction and mitochondrial damage after ischemia reperfusion. This protection was attributed to MitoQ in the mitochondria [119].

Since natural antioxidants given at high doses without side effects have been shown to decrease oxidative damage in $\mathrm{AD}$ mouse models and $\mathrm{AD}$ patients [33-43], there is a strong rationale for testing these mitochondrially targeted antioxidants in trials using $\mathrm{AD}$ cell and mouse models, and $\mathrm{AD}$ patients.

\section{MitoVitE}

MitoVitE is an antioxidant that consists of [2-3,4dihydro6-hydroxy-2,5,7,8tetra-methyl-2H-1-benzopyran-2-yl] and triphenylphosphonium bromide [86]. MitoVitE is a derivative of vitamin $\mathrm{E}$ that is targeted to mitochondria, and it was developed to study mitochondrial oxidative damage. MitoVitE is rapidly taken up by mitochondria, and the uptake lasts for $15 \mathrm{~min}$. Accumulation ratios of 5000-6000 unit have been achieved after incubating mitochondria with 1-20 $\mu \mathrm{M}$ MitoVitE [86]. MitoVitE is cytotoxic at $50 \mu \mathrm{M}$. The effects of MitoVitE have been tested in Jurkat cells. MitoVitE was found to reduce $\mathrm{H}_{2} \mathrm{O}_{2}$-induced caspase activity [120]; to prevent oxidative stress-induced cell death in cultured fibroblasts from Friederich Ataxia patients [115]; and at $(1 \mu \mathrm{M})$ concentration, to inhibit cytochrome $c$ release and caspase-3 activation, to inactivate complex 1 , and to restore mitochondrial membrane potential and proteosomal activity in bovine aortic epithelial cells [117].

\section{MitoPBN}

MitoPBN is an antioxidant consisting of [4-[4 (1,1-dimethylethyl) oxidoimino]-methyl]phenoxy]butyl] and triphenylphosphonium bromide [104, 121]. A mitochondrially targeted analog of MitoPBN was prepared to determine the effect of ROS and mitochondrial function in mitochondria, based on a selective PBN ( $\alpha$-phenyl-N-tert-butyl nitrone) reaction with carbon-centered radicals [104]. Similar to MitoQ and MitoVitE, MitoPBN was rapidly taken up by mitochondria, with a resulting concentration ranging from 2.2 to $4.0 \mathrm{mM}$. It has been reported that MitoPBN blocks the $\mathrm{O}$-induced activation of uncoupled proteins.

Recently, Poeggeler et al [122] developed an amphiphilic molecule, $\mathrm{N}$-[4-(octa-O-acetyllactobionamidomethylene) benzylidene]- $N$-[1,1-dimethyl-2-( $N$-octanoyl) amido]-ethylamine $N$-oxide, (LPBNAH, a derivative of $\alpha$-phenyl-Ntert-butyl nitrone) that exhibits profound antioxidant and neuroprotective activity and very efficiently antagonizes oxidotoxicity of primarily mitochondrial origin [122]. LPBNAH, when administered via food to rotifers, was found to decrease free radicals, to greatly enhance the survival of neurons, and to increase the life span of rotifers. The antiaging activity of LPBNAH exceeded that of other nitrone compounds, such as the parent compound PBN, by at least one order of magnitude. The development of such a neuroprotective antioxidant may lead to more safe and effective treatments of age-related diseases such as AD.

\section{AMINO ACID- AND PEPTIDE-BASED MITOCHONDRIALLY TARGETED ANTIOXIDANTS}

SS tetrapeptides are aromatic cationic peptides that contain the structural motif of alternating aromatic and basic amino acid residues, along with a $2^{\prime}, 6^{\prime}$-dimethyltyrosine residue [86]. These tetrapeptides are mitochondrially targeted antioxidants. Their antioxidant properties are derived from the related compound 3, 5-dimethyphenolis, a known phenolic antioxidant [123]. SS tetrapeptides were originally We prepared to develop centrally acting opiopoid analgesics $[124,125]$. The following SS tetreapeptide compounds have been developed for mitochondrial and cellular uptake studies: (1) Dmt-D-arg-Phe-Lys NH2 (SS-02); (2) Phe-D-ArgPhe-Lys-NH2 (SS-20); (3) D-Arg-Dmt-Lys-Phe-NH2 (SS31); and (4) Dmt-d-Arg-Phe-atnDAP-NH2 (SS-19) [86].

SS-02 neutralizes $\mathrm{H}_{2} \mathrm{O}_{2}$ and inhibits the oxidation of linoleic acid and low-density lipoproteins. SS-31 contains same amino acid residues, as does SS-02, but in an order that exhibits antioxidant properties. SS- 02 is taken up by Caco- 2 cells (derived from human colorectal adenocarcinoma), and its intracellular concentration is about 10 times greater than its extracellular concentration. SS-02 and SS-19 are rapidly taken up by isolated mitochondria from mouse liver, with accumulation in the mitochondria 105 -fold. The incubation of mitochondria with FCCP reduced the uptake of SS-19 by $20 \%$, suggesting partial potential-dependent uptake [86]. Treatment of SS-02 with digitonin showed that about $85 \%$ of SS-02 is present in the mitoplast (inner membrane plus matrix).

Recently, Zhao et al [106] developed peptide antioxidants that target the inner mitochondrial membrane. These antioxidants were used to investigate the role of ROS and the mitochondrial permeable transition of $3 \mathrm{NP}$ in cell death caused by the peptides [t-butylhydroperoxide (tBHP) and 3nitropropionic acid (3NP)]. The structural motif of tBHP and 3NP centers on alternating aromatic and basic amino acid residues, with dimethyltyrosine providing scavenging properties. BHP and 3NP were found to be cell-permeable 
and to concentrate at 1000-fold in the inner mitochondrial membrane. Peptide antioxidants potently reduced intracellular ROS and cell death caused by tBHP in neuronal N2a cells. These peptide antioxidants also decreased mitochondrial ROS production, inhibited mitochondrial permeability transition and swelling, and prevented cytochrome $c$ release induced by $\mathrm{Ca}^{2+}$ in isolated mitochondria. In addition, peptide antioxidants inhibited 3NP-induced mitochondrial permeability transition in isolated mitochondria and prevented mitochondrial depolarization in cells treated with 3NP. ROS and mitochondrial permeability transition have been implicated in myocardial stunning associated with reperfusion in ischemic hearts. Peptide antioxidants were found to potently improve contractile force in an ex vivo heart model. It is noteworthy that peptide analogs without dimethyltyrosine did not inhibit mitochondrial ROS generation or swelling, and did not prevent myocardial stunning. These results clearly suggest that ROS underlies the cellular toxicity of tBHP and 3NP, and that ROS may mediate cytochrome $c$ release via a mitochondrial permeability transition. Peptide antioxidants may be very beneficial in the treatment of aging and diseases associated with oxidative stress [106].

Further, Zhao et al examined the ability of a novel, cellpenetrating, mitochondrially targeted peptide antioxidant to protect against oxidant-induced mitochondrial dysfunction and apoptosis in two neuronal cell lines [105]. Treatment of neuronal cell lines with tBHP for 24 hours resulted in lipid peroxidation, significant cell death via apoptosis in both $\mathrm{N} 2 \mathrm{a}$ and SH-SY5Y cells, phosphatidylserine translocation, nuclear condensation, and increased caspase activity. When treated with $\mathrm{tBHP}$, the $\mathrm{N} 2 \mathrm{a}$ and SH-SY5Y cells showed a significant increase in intracellular ROS, mitochondrial depolarization, and reduced mitochondrial viability. Concurrent treatment with $<1 \mathrm{nM}$ SS-31 significantly decreased intracellular ROS, increased mitochondrial potential, and prevented tBHP-induced apoptosis.

The remarkable potency of SS-31 can be explained by its extensive cellular uptake and selective partitioning into mitochondria. Intracellular concentrations of [3H]SS-31 were 6fold higher than extracellular concentrations. Studies using isolated mitochondria revealed that $[3 \mathrm{H}] \mathrm{SS}-31$ was concentrated approximately 5000-fold in the mitochondrial pellet. By concentrating in the inner mitochondrial membrane, SS31 became localized to the site of ROS production, and protected against mitochondrial oxidative damage and against further ROS production. SS-31 represents a novel platform for mitochondria-targeted antioxidants with broad therapeutic potential [105].

\section{CONCLUSIONS}

Recent advances in molecular, cellular, and animal model studies have revealed that mitochondria are the major source of free radical generation and of oxidative damage in aging and age-related neurodegenerative diseases. It is possible that age-related mitochondrial abnormalities and oxidative damage are major contributing factors for late-onset $\mathrm{AD}$. To stop or delay the progression of late-onset $\mathrm{AD}$, and also to reduce disease symptoms, several therapeutic strategies have been developed, including anti-inflammatory, antioxidant, and antiamyloid approaches. Among these, mitochondrial antioxidant therapy reduces $\mathrm{AD}$ pathology more than any other approach. However, until recently, a major limitation in developing antioxidant therapies for $\mathrm{AD}$ patients has been the inability to enhance antioxidant levels in mitochondria. There has been a breakthrough in the mitochondrial targeting of antioxidants. Mitochondrially targeted antioxidants have been developed, which preferentially enter the mitochondria-at several hundred-fold more than they enter natural antioxidants-where they rapidly neutralize free radicals and decrease mitochondrial toxicity. However, further research is needed to determine whether these mitochondrially targeted antioxidants can be used in mouse models of aging and in age-related neurodegenerative diseases such as Alzheimer's, Parkinson's, and Huntington's.

\section{ABBREVIATIONS}

$\begin{array}{ll}\text { 3NP } & \text { 3-nitropropionic acid } \\ \text { ABAD } & \text { alcohol dehydrogenase } \\ \text { A } \beta & \text { amyloid beta } \\ \text { ACh } & \text { acetylcholine } \\ \text { AD } & \text { Alzheimer's disease } \\ \text { ApoE } & \text { apolipoprotein E } \\ \text { APP } & \text { amyloid precursor protein } \\ \text { ATP } & \text { adenosine triphosphate } \\ \text { BChE } & \text { butylcholinesterase } \\ \text { ChAT } & \text { choline acetyltransferase } \\ \text { ETC } & \text { electron transport chain } \\ \mathrm{H}_{2} \mathrm{O}_{2} & \text { hydrogen peroxide } \\ \text { MCAT } & \text { mitochondrial catalase } \\ \text { MitoVitE } & \text { mitochondrially targeted vitamin E } \\ \text { MitoQ } & \text { mitochondrially targeted ubiquinone } \\ \text { MitoPBN } & \text { mitochondrially targeted } \alpha \text {-phenyl-N-tert-butyl } \\ \text { nitrone } & \text { neuroblastoma } \\ \text { NCAT } & \text { nuclear catalase } \\ \text { NFT } & \text { neurofibrillary tangle } \\ \mathrm{O}_{2}^{\bullet-} & \text { superoxide anion } \\ \text { PBN } & \alpha \text {-phenyl-N-tert-butyl nitrone } \\ \text { ROS } & \text { reactive oxygen species } \\ \text { SOD } & \text { superoxide dismutase } \\ \text { tBHP } & \text { t-butylhydroperoxide } \\ & \end{array}$

\section{REFERENCES}

[1] Selkoe DJ. Alzheimer's disease: genes, proteins, and therapy. Physiological Reviews. 2001;81(2):741-766.

[2] Mattson MP. Pathways towards and away from Alzheimer's disease. Nature. 2004;430(7000):631-639.

[3] Reddy PH, McWeeney S. Mapping cellular transcriptosomes in autopsied Alzheimer's disease subjects and relevant animal models. Neurobiology of Aging. 2005. September 9; [Epub ahead of print].

[4] Anekonda TS, Reddy PH. Can herbs provide a new generation of drugs for treating Alzheimer's disease? Brain Research. Brain Research Reviews. 2005;50(2):361-376. 
[5] Reddy PH, Beal MF. Are mitochondria critical in the pathogenesis of Alzheimer's disease? Brain Research. Brain Research Reviews. 2005;49(3):618-632. Epub 2005 April 19.

[6] Reddy PH. Amyloid precursor protein-mediated free radicals and oxidative damage: implications for the development and progression of Alzheimer's disease. Journal of Neurochemistry. 2006;96(1):1-13.

[7] Zhu X, Lee HG, Casadesus G, et al. Oxidative imbalance in Alzheimer's disease. Molecular Neurobiology. 2005;31(13):205-217.

[8] Swerdlow RH, Khan SM. A “mitochondrial cascade hypothesis” for sporadic Alzheimer's disease. Medical Hypotheses. 2004;63(1):8-20.

[9] Sullivan PG, Brown MR. Mitochondrial aging and dysfunction in Alzheimer's disease. Progress in Neuro-Psychopharmacology \& Biological Psychiatry. 2005;29(3):407-410.

[10] Raber J, Huang Y, Ashford JW. ApoE genotype accounts for the vast majority of AD risk and AD pathology. Neurobiology of Aging. 2004;25(5):641-650.

[11] Raber J. Androgens, apoE, and Alzheimer's disease. Science of Aging Knowledge Environment. 2004;2004(11):re2.

[12] de la Monte SM, Wands JR. Review of insulin and insulinlike growth factor expression, signaling, and malfunction in the central nervous system: relevance to Alzheimer's disease. Journal of Alzheimer's Disease. 2005;7(1):45-61.

[13] Kitazawa M, Yamasaki TR, LaFerla FM. Microglia as a Potential Bridge between the Amyloid \{beta\}-Peptide and Tau. Annals of the New York Academy of Sciences. 2004;1035:85103.

[14] Oddo S, Billings L, Kesslak JP, Cribbs DH, LaFerla FM. Abeta immunotherapy leads to clearance of early, but not late, hyperphosphorylated tau aggregates via the proteasome. Neuron. 2004;43(3):321-332.

[15] Oddo S, Caccamo A, Tran L, et al. Temporal profile of amyloid-beta (Abeta) oligomerization in an in vivo model of Alzheimer disease. A link between Abeta and tau pathology. The Journal of Biological Chemistry. 2006;281(3):1599-1604. November 10; [Epub ahead of print].

[16] Oddo S, Caccamo A, Shepherd JD, et al. Triple-transgenic model of Alzheimer's disease with plaques and tangles: intracellular Abeta and synaptic dysfunction. Neuron. 2003;39(3): 409-421.

[17] Morgan D, Gordon MN, Tan J, Wilcock D, Rojiani AM. Dynamic complexity of the microglial activation response in transgenic models of amyloid deposition: implications for Alzheimer therapeutics. Journal of Neuropathology and Experimental Neurology. 2005;64(9):743-753.

[18] Lustbader JW, Cirilli M, Lin C, et al. ABAD directly links Abeta to mitochondrial toxicity in Alzheimer's disease. Science. 2004;304(5669):448-452.

[19] Crouch PJ, Blake R, Duce JA, et al. Copper-dependent inhibition of human cytochrome c oxidase by a dimeric conformer of amyloid-beta1-42. Journal of Neuroscience. 2005;25(3): 672-679.

[20] Nordberg A, Hellstrom-Lindahl E, Lee M, et al. Chronic nicotine treatment reduces beta-amyloidosis in the brain of a mouse model of Alzheimer's disease (APPsw). Journal of Neurochemistry. 2002;81(3):655-658.

[21] Reddy PH, McWeeney S, Park BS, et al. Gene expression profiles of transcripts in amyloid precursor protein transgenic mice: up-regulation of mitochondrial metabolism and apoptotic genes is an early cellular change in Alzheimer's disease. Human Molecular Genetics. 2004;13(12):1225-1240. Epub 2004 April 28.
[22] Reddy PH, Mani G, Park BS, et al. Differential loss of synaptic proteins in Alzheimer's disease: implications for synaptic dysfunction. Journal of Alzheimer's Disease. 2005;7(2):103117. discussion 173-80.

[23] Manczak M, Park BS, Jung Y, Reddy PH. Differential expression of oxidative phosphorylation genes in patients with Alzheimer's disease: implications for early mitochondrial dysfunction and oxidative damage. Neuromolecular Medicine. 2004;5(2):147-162.

[24] Hirai K, Aliev G, Nunomura A, et al. Mitochondrial abnormalities in Alzheimer's disease. Journal of Neuroscience. 2001;21(9):3017-3023.

[25] Schenk D, Barbour R, Dunn W, et al. Immunization with amyloid-beta attenuates Alzheimer-disease-like pathology in the PDAPP mouse. Nature. 1999;400(6740):173-177.

[26] Morgan D, Diamond DM, Gottschall PE, et al. A beta peptide vaccination prevents memory loss in an animal model of Alzheimer's disease. Nature. 2000;408(6815):982-985.

[27] DeMattos RB, Bales KR, Cummins DJ, Dodart JC, Paul SM, Holtzman DM. Peripheral anti-A beta antibody alters CNS and plasma A beta clearance and decreases brain A beta burden in a mouse model of Alzheimer's disease. Proceedings of the National Academy of Sciences of the United States of America. 2001;98(15):8850-8855.

[28] Gelinas DS, DaSilva K, Fenili D, St George-Hyslop P, McLaurin J. Immunotherapy for Alzheimer's disease. Proceedings of the National Academy of Sciences of the United States of America. 2004;101(suppl 2):14657-14662. Epub 2004 August 5.

[29] McGeer PL, McGeer EG. The inflammatory response system of brain: implications for therapy of Alzheimer and other neurodegenerative diseases. Brain Research. Brain Research Reviews. 1995;21(2):195-218.

[30] Launer LJ. Nonsteroidal anti-inflammatory drugs and Alzheimer disease: what's next? The Journal of the American Medical Association. 2003;289(21):2865-2867.

[31] Gasparini L, Ongini E, Wenk G. Non-steroidal anti-inflammatory drugs (NSAIDs) in Alzheimer's disease: old and new mechanisms of action. Journal of Neurochemistry. 2004;91(3): 521-536.

[32] Gasparini L, Ongini E, Wilcock D, Morgan D. Activity of flurbiprofen and chemically related anti-inflammatory drugs in models of Alzheimer's disease. Brain Research. Brain Research Reviews. 2005;48(2):400-408.

[33] Nakashima H, Ishihara T, Yokota O, et al. Effects of alphatocopherol on an animal model of tauopathies. Free Radical Biology \& Medicine. 2004;37(2):176-186.

[34] Conte V, Uryu K, Fujimoto S, et al. Vitamin E reduces amyloidosis and improves cognitive function in Tg2576 mice following repetitive concussive brain injury. Journal of Neurochemistry. 2004;90(3):758-764.

[35] Sung S, Yao Y, Uryu K, et al. Early vitamin E supplementation in young but not aged mice reduces Abeta levels and amyloid deposition in a transgenic model of Alzheimer's disease. The FASEB Journal. 2004;18(2):323-325.

[36] Matsubara E, Bryant-Thomas T, Pacheco Quinto J, et al. Melatonin increases survival and inhibits oxidative and amyloid pathology in a transgenic model of Alzheimer's disease. Journal of Neurochemistry. 2003;85(5):1101-1108.

[37] Stackman RW, Eckenstein F, Frei B, Kulhanek D, Nowlin J, Quinn JF. Prevention of age-related spatial memory deficits in a transgenic mouse model of Alzheimer's disease by chronic Ginkgo biloba treatment. Experimental Neurology. 2003;184(1):510-520. 
[38] Yang F, Lim GP, Begum AN, et al. Curcumin inhibits formation of amyloid beta oligomers and fibrils, binds plaques, and reduces amyloid in vivo. The Journal of Biological Chemistry. 2005;280(7):5892-5901.

[39] Morris MC, Beckett LA, Scherr PA, et al. Vitamin E and vitamin C supplement use and risk of incident Alzheimer disease. Alzheimer Disease and Associated Disorders. 1998;12(3):121126.

[40] Morris MC, Evans DA, Bienias JL, et al. Dietary intake of antioxidant nutrients and the risk of incident Alzheimer disease in a biracial community study. The Journal of the American Medical Association. 2002;287(24):3230-3237.

[41] Morris MC, Evans DA, Tangney CC, et al. Relation of the tocopherol forms to incident Alzheimer disease and to cognitive change. The American Journal of Clinical Nutrition. 2005;81(2):508-514.

[42] Grundman M, Petersen RC, Ferris SH, et al. Mild cognitive impairment can be distinguished from Alzheimer disease and normal aging for clinical trials. Archives of Neurology. 2004;61(1):59-66.

[43] Zandi PP, Anthony JC, Khachaturian AS, et al. Reduced risk of Alzheimer disease in users of antioxidant vitamin supplements: the Cache County Study. Archives of Neurology. 2004;61(1):82-88.

[44] Clarke NA, Francis PT. Cholinergic and glutamatergic drugs in Alzheimer's disease therapy. Expert Review of Neurotherapeutics. 2005;5(5):671-682.

[45] Racchi M, Mazzucchelli M, Lenzken SC, Porrello E, Lanni C, Govoni S. Role of acetylcholinesterase inhibitors in the regulation of amyloid beta precursor protein (AbetaPP) metabolism. Chemico-Biological Interactions. 2005;157-158: 335-338. November 16; [Epub ahead of print].

[46] Kaduszkiewicz H, Zimmermann T, Beck-Bornholdt HP, van den Bussche H. Cholinesterase inhibitors for patients with Alzheimer's disease: systematic review of randomised clinical trials. British Medical Journal. 2005;331(7512):321-327.

[47] Greig NH, Utsuki T, Ingram DK, et al. Selective butyrylcholinesterase inhibition elevates brain acetylcholine, augments learning and lowers Alzheimer beta-amyloid peptide in rodent. Proceedings of the National Academy of Sciences of the United States of America. 2005;102(47):17213-17218.

[48] Ellis JM. Cholinesterase inhibitors in the treatment of dementia. The Journal of the American Osteopathic Association. 2005;105(3):145-158.

[49] Zimmermann M, Borroni B, Cattabeni F, Padovani A, Di Luca M. Cholinesterase inhibitors influence APP metabolism in Alzheimer disease patients. Neurobiology of Disease. 2005;19(1-2):237-242.

[50] Wilkinson DG, Francis PT, Schwam E, Payne-Parrish J. Cholinesterase inhibitors used in the treatment of Alzheimer's disease: the relationship between pharmacological effects and clinical efficacy. Drugs \& Aging. 2004;21(7): 453-478.

[51] Lahiri DK, Rogers JT, Greig NH, Sambamurti K. Rationale for the development of cholinesterase inhibitors as anti-Alzheimer agents. Current Pharmaceutical Design. 2004;10(25):3111-3119.

[52] Zhu X, Raina AK, Perry G, Smith MA. Alzheimer's disease: the two-hit hypothesis. Lancet Neurology. 2004;3(4):219-226.

[53] Herrup K, Neve R, Ackerman SL, Copani A. Divide and die: cell cycle events as triggers of nerve cell death. The Journal of Neuroscience. 2004;24(42):9232-9239.
[54] Neve RL, McPhie DL. The cell cycle as a therapeutic target for Alzheimer's disease. Pharmacology \& Therapeutics. 2005. November 7; [Epub ahead of print].

[55] Tang MX, Jacobs D, Stern Y, et al. Effect of oestrogen during menopause on risk and age at onset of Alzheimer's disease. Lancet. 1996;348(9025):429-432.

[56] Marlatt MW, Webber KM, Moreira PI, et al. Therapeutic opportunities in Alzheimer disease: one for all or all for one? Current Medicinal Chemistry. 2005;12(10):1137-1147.

[57] Casadesus G, Zhu X, Atwood CS, et al. Beyond estrogen: targeting gonadotropin hormones in the treatment of Alzheimer's disease. Current Drug Targets. CNS and Neurological Disorders. 2004;3(4):281-285.

[58] Koldamova RP, Lefterov IM, Staufenbiel M, et al. The liver X receptor ligand T0901317 decreases amyloid beta production in vitro and in a mouse model of Alzheimer's disease. The Journal of Biological Chemistry. 2005;280(6):4079-4088.

[59] Ognibene E, Middei S, Daniele S, et al. Aspects of spatial memory and behavioral disinhibition in Tg2576 transgenic mice as a model of Alzheimer's disease. Behavioural Brain Research. 2005;156(2):225-232.

[60] Walsh DM, Townsend M, Podlisny MB, et al. Certain inhibitors of synthetic amyloid beta-peptide (Abeta) fibrillogenesis block oligomerization of natural Abeta and thereby rescue long-term potentiation. The Journal of Neuroscience. 2005;25(10):2455-2462.

[61] Abbas N, Bednar I, Mix E, et al. Up-regulation of the inflammatory cytokines IFN-gamma and IL-12 and downregulation of IL-4 in cerebral cortex regions of APP(SWE) transgenic mice. Journal of Neuroimmunology. 2002;126(12):50-57.

[62] Tehranian R, Andell-Jonsson S, Beni SM, et al. Improved recovery and delayed cytokine induction after closed head injury in mice with central overexpression of the secreted isoform of the interleukin-1 receptor antagonist. Journal of $\mathrm{Neu}$ rotrauma. 2002;19(8):939-951.

[63] Kasa P, Rakonczay Z, Gulya K. The cholinergic system in Alzheimer's disease. Progress in Neurobiology. 1997;52(6): 511-535.

[64] Lovell MA, Ehmann WD, Butler SM, Markesbery WR. Elevated thiobarbituric acid-reactive substances and antioxidant enzyme activity in the brain in Alzheimer's disease. Neurology. 1995;45(8):1594-1601.

[65] Markesbery WR, Carney JM. Oxidative alterations in Alzheimer's disease. Brain Pathology. 1999;9(1):133-146.

[66] Pappolla MA, Omar RA, Kim KS, Robakis NK. Immunohistochemical evidence of oxidative [corrected] stress in Alzheimer's disease. The American Journal of Pathology. 1992;140(3):621-628. Erratum in: The American Journal of Pathology. 1996;149(5):1770.

[67] Pappolla MA, Chyan YJ, Poeggeler B, et al. Alzheimer beta protein mediated oxidative damage of mitochondrial DNA: prevention by melatonin. Journal of Pineal Research. 1999; 27(4):226-229.

[68] Bozner P, Grishko V, LeDoux SP, Wilson GL, Chyan YC, Pappolla MA. The amyloid beta protein induces oxidative damage of mitochondrial DNA. Journal of Neuropathology and Experimental Neurology. 1997;56(12):1356-1362.

[69] Lyras L, Perry RH, Perry EK, et al. Oxidative damage to proteins, lipids, and DNA in cortical brain regions from patients with dementia with Lewy bodies. Journal of Neurochemistry. 1998;71(1):302-312.

[70] Butterfield DA, Drake J, Pocernich C, Castegna A. Evidence of oxidative damage in Alzheimer's disease brain: central 
role for amyloid beta-peptide. Trends in Molecular Medicine. 2001;7(12):548-554.

[71] Meda L, Cassatella MA, Szendrei GI, et al. Activation of microglial cells by beta-amyloid protein and interferon-gamma. Nature. 1995;374(6523):647-650.

[72] Qin L, Liu Y, Cooper C, Liu B, Wilson B, Hong JS. Microglia enhance beta-amyloid peptide-induced toxicity in cortical and mesencephalic neurons by producing reactive oxygen species. Journal of Neurochemistry. 2002;83(4):973-983.

[73] Olanow CW. An introduction to the free radical hypothesis in Parkinson's disease. Annals of Neurology. 1992;32(suppl):S2S9.

[74] Varadarajan S, Yatin S, Aksenova M, Butterfield DA. Review: Alzheimer's amyloid beta-peptide-associated free radical oxidative stress and neurotoxicity. Journal of Structural Biology. 2000;130(2-3):184-208.

[75] Smith MA, Kutty RK, Richey PL, et al. Heme oxygenase-1 is associated with the neurofibrillary pathology of Alzheimer's disease. The American Journal of Pathology. 1994;145(1):4247.

[76] Smith MA, Perry G, Richey PL, et al. Oxidative damage in Alzheimer's. Nature. 1996;382(6587):120-121.

[77] Sayre LM, Zelasko DA, Harris PL, Perry G, Salomon RG, Smith MA. 4-Hydroxynonenal-derived advanced lipid peroxidation end products are increased in Alzheimer's disease. Journal of Neurochemistry. 1997;68(5):2092-2097.

[78] Good PF, Werner P, Hsu A, Olanow CW, Perl DP. Evidence of neuronal oxidative damage in Alzheimer's disease. The American Journal of Pathology. 1996;149(1):21-28.

[79] Behl C. Oxidative stress in Alzheimer's disease: implications for prevention and therapy. Sub-Cellular Biochemistry. 2005;38:65-78.

[80] Cadenas E, Davies KJ. Mitochondrial free radical generation, oxidative stress, and aging. Free Radical Biology \& Medicine. 2000;29(3-4):222-230.

[81] Cadenas E. Mitochondrial free radical production and cell signaling. Molecular Aspects of Medicine. 2004;25(1-2):17-26.

[82] Turrens JF. Mitochondrial formation of reactive oxygen species. The Journal of Physiology. 2003;552(pt 2):335-344.

[83] Muller FL, Liu Y, Van Remmen H. Complex III releases superoxide to both sides of the inner mitochondrial membrane. The Journal of Biological Chemistry. 2004;279(47):4906449073.

[84] Starkov AA, Fiskum G, Chinopoulos C, et al. Mitochondrial alpha-ketoglutarate dehydrogenase complex generates reactive oxygen species. The Journal of Neuroscience. 2004;24(36): $7779-7788$.

[85] Wallace DC. Mitochondrial diseases in man and mouse. Science. 1999;283(5407):1482-1488.

[86] Sheu SS, Nauduri D, Anders MW. Targeting antioxidants to mitochondria: a new therapeutic direction. Biochimica et Biophysica Acta. 2006;1762(2):256-265.

[87] Beal MF. Mitochondria take center stage in aging and neurodegeneration. Annals of Neurology. 2005;58(4):495-505.

[88] Dawson R Jr, Beal MF, Bondy SC, Di Monte DA, Isom GE. Excitotoxins, aging, and environmental neurotoxins: implications for understanding human neurodegenerative diseases. Toxicology and Applied Pharmacology. 1995;134(1):117.

[89] Richardson JR, Quan Y, Sherer TB, Greenamyre JT, Miller GW. Paraquat neurotoxicity is distinct from that of MPTP and rotenone. Toxicological Sciences. 2005;88(1):193-201.

[90] McCarthy S, Somayajulu M, Sikorska M, Borowy-Borowski $\mathrm{H}$, Pandey S. Paraquat induces oxidative stress and neuronal cell death; neuroprotection by water-soluble Coenzyme Q10. Toxicology and Applied Pharmacology. 2004;201(1):21-31.

[91] Brown MR, Geddes JW, Sullivan PG. Brain region-specific, age-related, alterations in mitochondrial responses to elevated calcium. Journal of Bioenergetics and Biomembranes. 2004;36(4):401-406.

[92] Abramov AY, Duchen MR. The role of an astrocytic NADPH oxidase in the neurotoxicity of amyloid beta peptides. Philosophical Transactions of the Royal Society of London. Series B, Biological Sciences. 2005;360(1464):2309-2314.

[93] Sullivan PG, Rabchevsky AG, Keller JN, et al. Intrinsic differences in brain and spinal cord mitochondria: implication for therapeutic interventions. The Journal of Comparative Neurology. 2004;474(4):524-534.

[94] Cardoso SM, Santos S, Swerdlow RH, Oliveira CR. Functional mitochondria are required for amyloid beta-mediated neurotoxicity. The FASEB Journal. 2001;15(8):1439-1441.

[95] Anandatheerthavarada HK, Biswas G, Robin MA, Avadhani NG. Mitochondrial targeting and a novel transmembrane arrest of Alzheimer's amyloid precursor protein impairs mitochondrial function in neuronal cells. The Journal of Cell Biology. 2003;161(1):41-54.

[96] Melov S, Wolf N, Strozyk D, Doctrow SR, Bush AI. Mice transgenic for Alzheimer disease beta-amyloid develop lens cataracts that are rescued by antioxidant treatment. Free Radical Biology \& Medicine. 2005;38(2):258-261.

[97] Zhang ZJ, Qian YH, Hu HT, Yang J, Yang GD. The herbal medicine Dipsacus asper wall extract reduces the cognitive deficits and overexpression of beta-amyloid protein induced by aluminum exposure. Life Sciences. 2003;73(19):24432454.

[98] Krzepilko A, Swiecilo A, Wawryn J, et al. Ascorbate restores lifespan of superoxide-dismutase deficient yeast. Free Radical Research. 2004;38(9):1019-1024.

[99] Ruan H, Tang XD, Chen ML, et al. High-quality life extension by the enzyme peptide methionine sulfoxide reductase. Proceedings of the National Academy of Sciences of the United States of America. 2002;99(5):2748-2753. Epub 2002 February 26.

[100] Magwere T, West M, Riyahi K, Murphy MP, Smith RA, Partridge L. The effects of exogenous antioxidants on lifespan and oxidative stress resistance in Drosophila melanogaster. Mechanisms of Ageing and Development. 2006;127(4):356370. [Epub ahead of print].

[101] Schriner SE, Linford NJ, Martin GM, et al. Extension of murine life span by overexpression of catalase targeted to mitochondria. Science. 2005;308(5730):1909-1911.

[102] Kelso GF, Porteous CM, Coulter CV, et al. Selective targeting of a redox-active ubiquinone to mitochondria within cells: antioxidant and antiapoptotic properties. The Journal of Biological Chemistry. 2001;276(7):4588-4596.

[103] Smith RA, Porteous CM, Coulter CV, Murphy MP. Selective targeting of an antioxidant to mitochondria. European Journal of Biochemistry. 1999;263(3):709-716.

[104] Murphy MP, Echtay KS, Blaikie FH, et al. Superoxide activates uncoupling proteins by generating carbon-centered radicals and initiating lipid peroxidation: studies using a mitochondria-targeted spin trap derived from alpha-phenylN-tert-butylnitrone. The Journal of Biological Chemistry. 2003;278(49):48534-48545.

[105] Zhao K, Zhao GM, Wu D, et al. Cell-permeable peptide antioxidants targeted to inner mitochondrial membrane inhibit mitochondrial swelling, oxidative cell death, 
and reperfusion injury. The Journal of Biological Chemistry. 2004;279(33):34682-34690. Epub 2004 June 2.

[106] Zhao K, Luo G, Giannelli S, Szeto HH. Mitochondriatargeted peptide prevents mitochondrial depolarization and apoptosis induced by tert-butyl hydroperoxide in neuronal cell lines. Biochemical Pharmacology. 2005;70(12):17961806. Epub 2005 October 10.

[107] Murphy MP, Smith RA. Drug delivery to mitochondria: the key to mitochondrial medicine. Advanced Drug Delivery Reviews. 2000;41(2):235-250.

[108] Murphy MP. Selective targeting of bioactive compounds to mitochondria. Trends in Biotechnology. 1997;15(8):326-330.

[109] Crane FL. Hydroquinone dehydrogenases. Annual Review of Biochemistry. 1977;46:439-469.

[110] Kagan VE, Serbinova EA, Stoyanovsky DA, Khwaja S, Packer L. Assay of ubiquinones and ubiquinols as antioxidants. Methods in Enzymology. 1994;234:343-354.

[111] Maguire JJ, Wilson DS, Packer L. Mitochondrial electron transport-linked tocopheroxyl radical reduction. The Journal of Biological Chemistry. 1989;264(36):21462-21465.

[112] Ernster L, Forsmark P, Nordenbrand K. The mode of action of lipid-soluble antioxidants in biological membranes: relationship between the effects of ubiquinol and vitamin $\mathrm{E}$ as inhibitors of lipid peroxidation in submitochondrial particles. BioFactors. 1992;3(4):241-248.

[113] Ingold KU, Bowry VW, Stocker R, Walling C. Autoxidation of lipids and antioxidation by alpha-tocopherol and ubiquinol in homogeneous solution and in aqueous dispersions of lipids: unrecognized consequences of lipid particle size as exemplified by oxidation of human low density lipoprotein. Proceedings of the National Academy of Sciences of the United States of America. 1993;90(1):45-49.

[114] Hwang PM, Bunz F, Yu J, et al. Ferredoxin reductase affects p53-dependent, 5-fluorouracil-induced apoptosis in colorectal cancer cells. Nature Medicine. 2001;7(10):1111-1117.

[115] Jauslin ML, Meier T, Smith RA, Murphy MP. Mitochondriatargeted antioxidants protect Friedreich Ataxia fibroblasts from endogenous oxidative stress more effectively than untargeted antioxidants. The FASEB Journal. 2003;17(13):19721974.

[116] Bedogni B, Pani G, Colavitti R, et al. Redox regulation of cAMP-responsive element-binding protein and induction of manganous superoxide dismutase in nerve growth factordependent cell survival. The Journal of Biological Chemistry. 2003;278(19):16510-16519.

[117] Dhanasekaran A, Kotamraju S, Kalivendi SV, et al. Supplementation of endothelial cells with mitochondria-targeted antioxidants inhibit peroxide-induced mitochondrial iron uptake, oxidative damage, and apoptosis. The Journal of Biological Chemistry. 2004;279(36):37575-37587.

[118] Smith RA, Porteous CM, Gane AM, Murphy MP. Delivery of bioactive molecules to mitochondria in vivo. Proceedings of the National Academy of Sciences of the United States of America. 2003;100(9):5407-5412.

[119] Adlam VJ, Harrison JC, Porteous CM, et al. Targeting an antioxidant to mitochondria decreases cardiac ischemiareperfusion injury. The FASEB Journal. 2005;19(9):10881095.

[120] Hughes G, Murphy MP, Ledgerwood EC. Mitochondrial reactive oxygen species regulate the temporal activation of nuclear factor kappaB to modulate tumour necrosis factorinduced apoptosis: evidence from mitochondria-targeted antioxidants. The Biochemical Journal. 2005;389(pt 1):83-89.
[121] Han D, Antunes F, Canali R, Rettori D, Cadenas E. Voltagedependent anion channels control the release of the superoxide anion from mitochondria to cytosol. The Journal of Biological Chemistry. 2003;278(8):5557-5563.

[122] Poeggeler B, Durand G, Polidori A, et al. Mitochondrial medicine: neuroprotection and life extension by the new amphiphilic nitrone LPBNAH acting as a highly potent antioxidant agent. Journal of Neurochemistry. 2005;95(4):962-973.

[123] Wright JS, Capenter DJ, McKay DJ, Ingold KU. Theortical calculation of substituent effects on the $\mathrm{O}-\mathrm{H}$ bond strength of phenolic antioxidants related to vitamin E. Journal of the American Chemical Society. 1997:4245-4252.

[124] Zhao K, Luo G, Zhao GM, Schiller PW, Szeto HH. Transcellular transport of a highly polar 3+ net charge opioid tetrapeptide. The Journal of Pharmacology and Experimental Therapeutics. 2003;304(1):425-432.

[125] Zhao GM, Qian X, Schiller PW, Szeto HH. Comparison of [Dmt1]DALDA and DAMGO in binding and G protein activation at mu, delta, and kappa opioid receptors. The Journal of Pharmacology and Experimental Therapeutics. 2003; 307(3):947-954. 


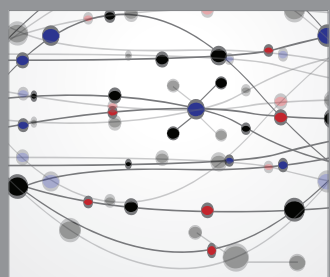

The Scientific World Journal
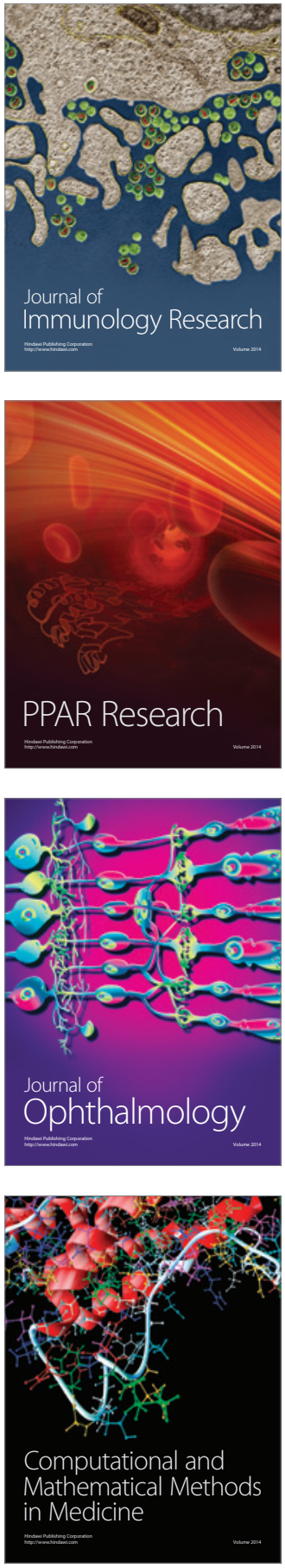

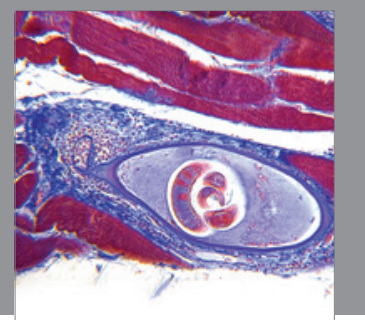

Gastroenterology

Research and Practice
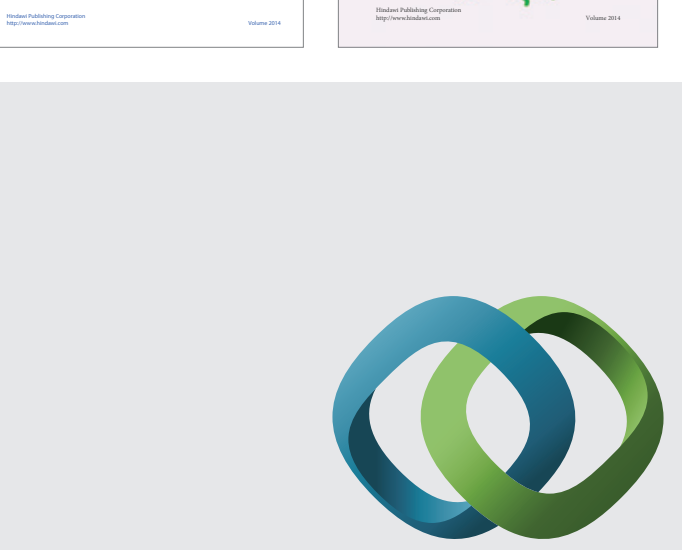

\section{Hindawi}

Submit your manuscripts at

http://www.hindawi.com
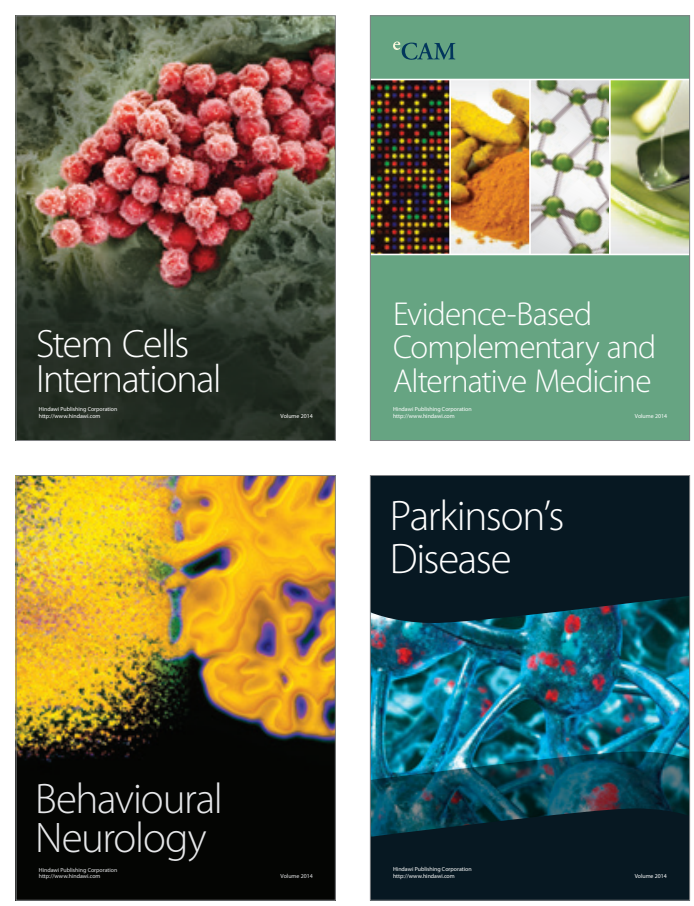

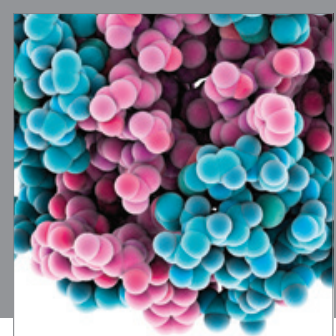

Journal of
Diabetes Research

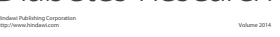

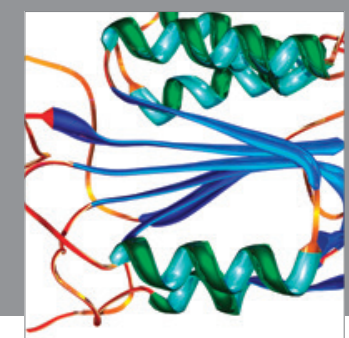

Disease Markers
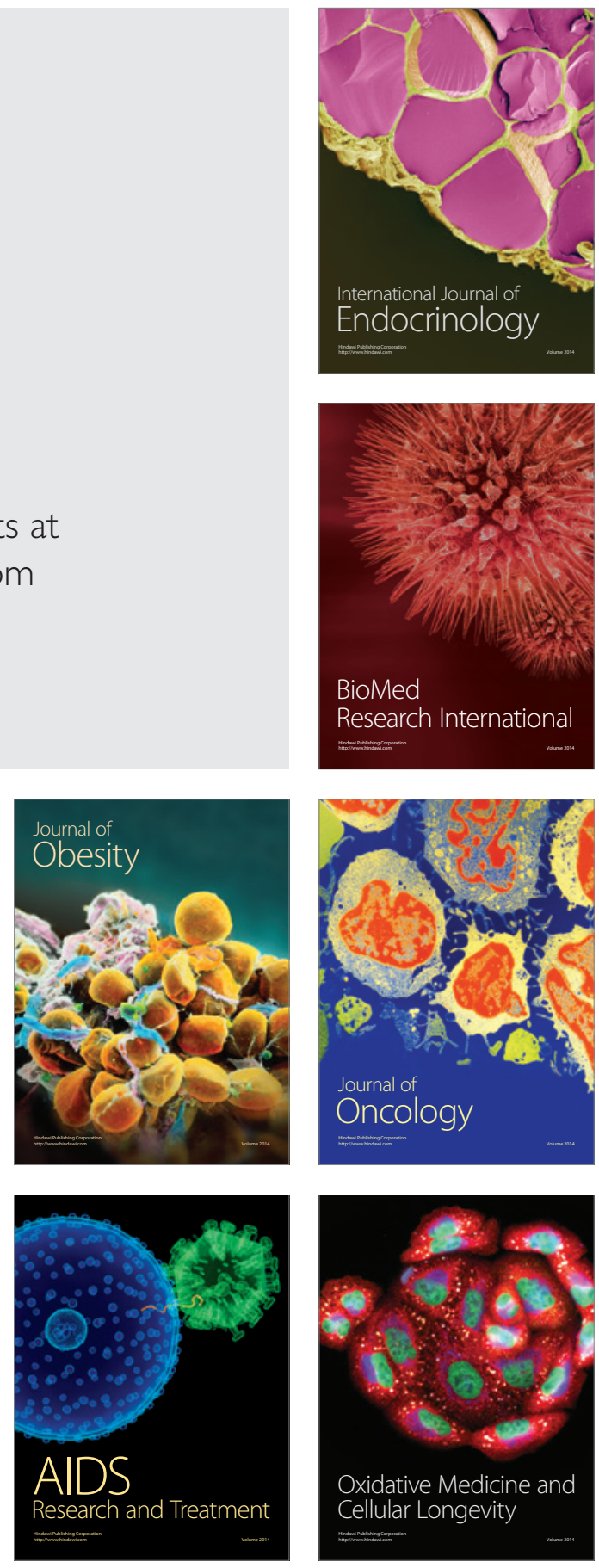